\title{
Monsplasty for Women After Massive Weight Loss
}

\author{
Benoit Hendrickx • Morris Ritz
}

Received: 1 November 2012/Accepted: 16 December 2012/Published online: 8 February 2013

(C) Springer Science+Business Media New York and International Society of Aesthetic Plastic Surgery 2013

Keywords Monsplasty $\cdot$ Pubic lift $\cdot$ Weight loss $\cdot$ Mons pubis

Level of Evidence $V$ This journal requires that authors assign a level of evidence to each article. For a full description of these Evidence-Based Medicine ratings, please refer to the Table of Contents or the online Instructions to Authors www.springer.com/00266

We read with interest the article by Marques et al. [1] on monsplasty in female patients after bariatric surgery for weight reduction. Most authors indeed focus on correction of the mons in women $[2,3]$. However, we would like to comment that a similar presentation is to be found in male patients after significant weight loss. Even though the pubic area is quite often neglected at the time of abdominoplasty, many male patients point this out as a particular problem.

Similar to female patients, many male weight loss patients have a hanging pouch in the pubic area that is resistant to the weight loss experienced in other regions of the body, with the described subsequent physical and psychological problems. Since this mass is covering a significant part of the penis, sexual function is probably even more impaired than in females [4]. The deformity can be surgically corrected in the male patient as part of an ellipse excision or as two triangular excisions in the left and right groin region. In some patients with a very obvious pouch, a direct vertical excision of the pouch may be indicated. Liposuction often is performed simultaneously to further reduce the volume.

We have identified this area in male patients and addressed it with very satisfactory results, except in one patient in whom scar contraction initially restricted erectile function but fortunately resolved over time. We hereby stress the importance of addressing the pubic region in all male weight loss patients at the time of body lifting or abdominoplasty.

Conflict of Interest The authors declare that they have no conflicts of interest to disclose.

\section{References}

1. Marques M, Modolin M, Cintra W, Gemperli R, Ferreira MC (2012) Monsplasty for women after massive weight loss. Aesthet Plast Surg 36:511-516

2. Alter G (2009) Management of the mons pubis and labia majora in the massive weight loss patient. Aesthet Surg J 29:432-442

3. Bloom J, Van Kouwenberg E, Davenport M, Koltz P, Shaw R, Gusenoff J (2012) Aesthetic and functional satisfaction after monsplasty in the massive weight loss population. Aesthet Surg J 32:877-885

4. Alter G (2012) Pubic contouring after massive weight loss in men and women: correction of hidden penis, mons ptosis, and labia majora enlargement. Plast Reconstr Surg 130:936-947 